\title{
MicroRNA-644a promotes apoptosis of hepatocellular carcinoma cells by downregulating the expression of heat shock factor 1
}

Wenjin Liang, Yong Liao, Zeming Li, Yan Wang, Siqi Zheng, Xiaochen Xu, Fulin Ran, Bo Tang ${ }^{*}$ and Zhenran Wang*

\begin{abstract}
In this study, we investigated the role of microRNA-644a (miR-644a) in the growth and survival of hepatocellular carcinoma (HCC) cells. MiR-644a levels were lower in HCC tissues than in adjacent peri-cancerous tissues $(n=135)$. MiR-644a expression was inversely correlated with heat shock factor 1 (HSF1) expression, tumour diameter and TNM stage. Moreover, HepG2 and SMMC-7721 cell lines showed lower miR-644a expression than normal L-O2 hepatocytes. MiR-644a overexpression in HepG2 and SMMC-7721 cells increased apoptosis by downregulating HSF1. Dual luciferase reporter assays confirmed the presence of a miR-644a binding site in the 3'-untranslated region (3'-UTR) of HSF1. Xenograft tumours derived from SMMC-7721 cells transfected with a miR-664a mimic showed less growth than tumours derived from untransfected controls. Protein chip analysis revealed that miR-644a-overexpressing SMMC-7721 and HepG2 cells strongly expressed pro-apoptotic BH3-only proteins, such as BID, BAD, BIM, SMAC, Apaf-1 and cleaved caspases-3 and -9. These findings suggest miR-644a promotes apoptosis in HCC cells by inhibiting HSF1.
\end{abstract}

Keywords: Hepatocellular carcinoma, miR-644a, HSF1, BH3-only protein, Apoptosis

\section{Introduction}

Hepatocellular carcinoma (HCC) is the primary malignancy of the liver and is the third leading cause of cancer deaths worldwide [1]. Despite significant progress in the diagnosis and treatment strategies, survival is extremely poor in HCC patients due to high recurrence rates $[2,3]$. Therefore, there is an urgent need to discover new mechanisms that aid early diagnosis and treatment of HCC.

MicroRNAs (miRNAs) are a class of small endogenous non-coding RNAs that regulate gene expression by inhibiting mRNA transcription or translation $[4,5]$. Moreover, miRNAs modulate growth, survival and other biological characteristics of tumour cells [6]. Several miRNAs have been identified as potential diagnostic and prognostic biomarkers for HCC; moreover, multiple miRNAs have shown potential as therapeutic targets in HCC [7]. Previously,

\footnotetext{
* Correspondence: dytangbo@163.com; gl190679136@163.com
Department of Gastrointestinal Surgery and Hepatobiliary Surgery, Guilin
Medical University, Affiliated Hospital, Guilin, Guangxi 541001, People's

* Correspondence: dytangbo@163.com; gl190679136@163.com
Department of Gastrointestinal Surgery and Hepatobiliary Surgery, Guilin
Medical University, Affiliated Hospital, Guilin, Guangxi 541001, People's

*Correspondence: dytangbo@163.com; gl190679136@163.com
Department of Gastrointestinal Surgery and Hepatobiliary Surgery, Guilin
Medical University, Affiliated Hospital, Guilin, Guangxi 541001, People's Republic of China
}

(c) The Author(s). 2018 Open Access This article is distributed under the terms of the Creative Commons Attribution 4.0 International License (http://creativecommons.org/licenses/by/4.0/), which permits unrestricted use, distribution, and reproduction in any medium, provided you give appropriate credit to the original author(s) and the source, provide a link to the Creative Commons license, and indicate if changes were made. The Creative Commons Public Domain Dedication waiver (http://creativecommons.org/publicdomain/zero/1.0/) applies to the data made available in this article, unless otherwise stated. that inhibited oesophageal cancer cell proliferation [8]. It also inhibited breast cancer cell proliferation and drug resistance [9]. However, the role of miR-644a in HCC is unknown. In a preliminary screening using TargetScan and miRanda analysis, we found a putative miR-644a binding site in the 3'-UTR of HSF1 (Liang et al., unpublished observation). This finding suggests that HSF1 might be a potential direct target gene for miR644a. Therefore, HSF1 was selected as the target gene for experimental analysis.

Heat shock factor 1 (HSF1) is a protective factor that is induced during various stress conditions including extrinsic environmental stress or intrinsic age-related deterioration [10]. HSF1 can also regulate protein homeostasis and degradation as well as malignant melanoma through the RAS-MEK signalling pathway [11]. Our research has shown that miR-644a expression is inversely correlated with HSF1 expression and promoted apoptosis in HCC cells by inhibiting HSF1, revealing a novel mechanism for miR-644a-mediated HCC progression that involves regulation by HSF1. 


\section{Results}

Low miR-644a expression negatively correlates with HSF1 expression, tumour diameter and TNM stages in HCC We performed in situ hybridization (ISH) and qRT-PCR analysis of miR-644a levels in surgically resected cancer and peri-cancerous liver tissues from $135 \mathrm{HCC}$ patients. We observed lower expression of miR-644a in HCC tissues than in adjacent peri-cancerous liver tissues $(P<$ 0.01, Fig. 1A-B). We also observed decreased miR-644a expression in HCC tissues (Fig. 1E).

Next, we analysed the correlation between miR-644a expression and the clinicopathological characteristics of the HCC patients. Based on the ROC curve analysis, we subdivided the $135 \mathrm{HCC}$ patients into high- and low-miR-644a-expressing groups (area under the curve $(\mathrm{AUC})=0.837, P<0.05$; Additional file 1: Figure S1A), and did the same for HSF1 (AUC $=0.902, P<0.05$; Additional file 1: Figure S1B). Moreover, the expression of miR-644a was negatively correlated with HSF1 expression $(P=0.004)$, tumour diameter $(P=0.001)$ and TNM stage $(P=0.001$; Table 1$)$.

Immunohistochemical analysis revealed higher HSF1 expression in HCC tissues than in adjacent peri-cancerous tissues $(P<0.01$, Fig. $1 C-D)$. Moreover, miR-644a expression was negatively correlated with HSF1 levels in HCC (Fig. 1F). Therefore, we postulated that miR-644a negatively regulates HSF1 expression.

\section{Prognostic significance of miR-644a expression in HCC patients}

We further analysed the prognostic significance of miR-644a expression in HCC patients based on their 5-year survival rates. Kaplan-Meier survival curves showed that HCC patients with low miR-644a expression were associated with lower overall survival (14 months vs. 68 months; $P<0.001)$ and recurrence-free survival (18 months vs. 65 months; $\mathrm{P}<0.001)$ than $\mathrm{HCC}$ patients with high miR-644a expression (Fig. 1G-H). Multivariate Cox regression analysis showed that low expression of miR-644a (relative risk $=0.350 ; P=0.001$ ) was an independent predictor of poor prognosis in HCC patients (Table 2). These results demonstrate that decreased expression of miR-644a correlates with poor prognosis in HCC patients.

\section{Correlation between miR-644a and HSF1 expression in HCC cell lines}

We verified the correlation between miR-644a and HSF1 by analysing their expression in multiple HCC cell lines and normal hepatocytes by qRT-PCR and western blotting, respectively. QRT-PCR analysis showed that miR-644a expression was lower in HepG2 and SMMC-7721 cells than in normal hepatocytes, L-O2, and the HCC cell lines sk-Hep1, MHCC-97 L and
QGY-7701 $(P<0.05$; Fig. 2A). Conversely, the mRNA and protein levels of HSF1 were higher in HepG2 and SMMC-7721 cells than in L-O2, sk-Hep1, MHCC-97 L and QGY-7701 cells $(\mathrm{P}<0.05$, Fig. 2B-C). Spearman's correlation analysis showed that miR-644a levels were negatively correlated with HSF1 mRNA levels $(P<0.05$, Fig. 2D).

\section{High miR-644a levels inhibit proliferation and promote apoptosis of HCC cells}

Next, we investigated the role of miR-644a in proliferation and survival of HCC cells by transfecting miR-644a mimics into HepG2 and SMMC-7721 cells (Fig. 3A). The CCK- 8 assay showed that miR-644a over-expression decreased the proliferation of HepG2 and SMMC-7721 cells more than in the corresponding controls (Fig. 3B). We further analysed the effects of miR-644a over-expression on apoptosis of HepG2 and SMMC-7721 cells by Annexin V/PI double staining. We observed that HepG2 and SMMC-7721 cells transfected with miR-644a mimics showed increased apoptosis compared with the corresponding controls (Fig. 3C). These results suggest that miR-644a negatively regulates proliferation and apoptosis of HCC cells.

\section{MiR-644a down-regulates HSF1 expression by binding to the HSF1 3'UTR}

TargetScan and miRanda analysis showed a putative miR-644a binding site in the 3'-UTR of HSF1 (Fig. 4A). Therefore, to prove that HSF1 was the target gene of miR-644a, we analysed HSF1 mRNA and protein levels in HepG2 and SMMC-7721 cells transfected with miR-644a mimics or miR-644a inhibitors. We observed that the miR-644a inhibitor increased HSF1 mRNA and protein expression, whereas the miR-644a mimic decreased HSF1 mRNA and protein levels in HepG2 and SMMC-7721 cells (Fig. 4B). Then, we investigated the correlation between miR-644a and HSF1 by using a dual luciferase reporter assay after co-transfecting HepG2 and SMMC-7721 cells with the luciferase reporter vector containing wild-type (wt) or mutant (mut) HSF13'UTR segments and miR-644a mimic or control miRNA. We observed a decreased relative luciferase activity in HCC cells co-transfected with miR-644a mimic and wild-type HSF1 3'UTR, whereas relative luciferase activity was normal in cells co-transfected with mutant HSF1 3'UTR and miR-644a mimics (Fig. 4D-E). These results showed that miR-644a down-regulates HSF1 expression.

\section{HSF1 promotes proliferation and survival of HCC cells}

Next, we analysed the proliferation, colony formation and apoptosis of HCC cells transfected with HSF1-siRNA. We 


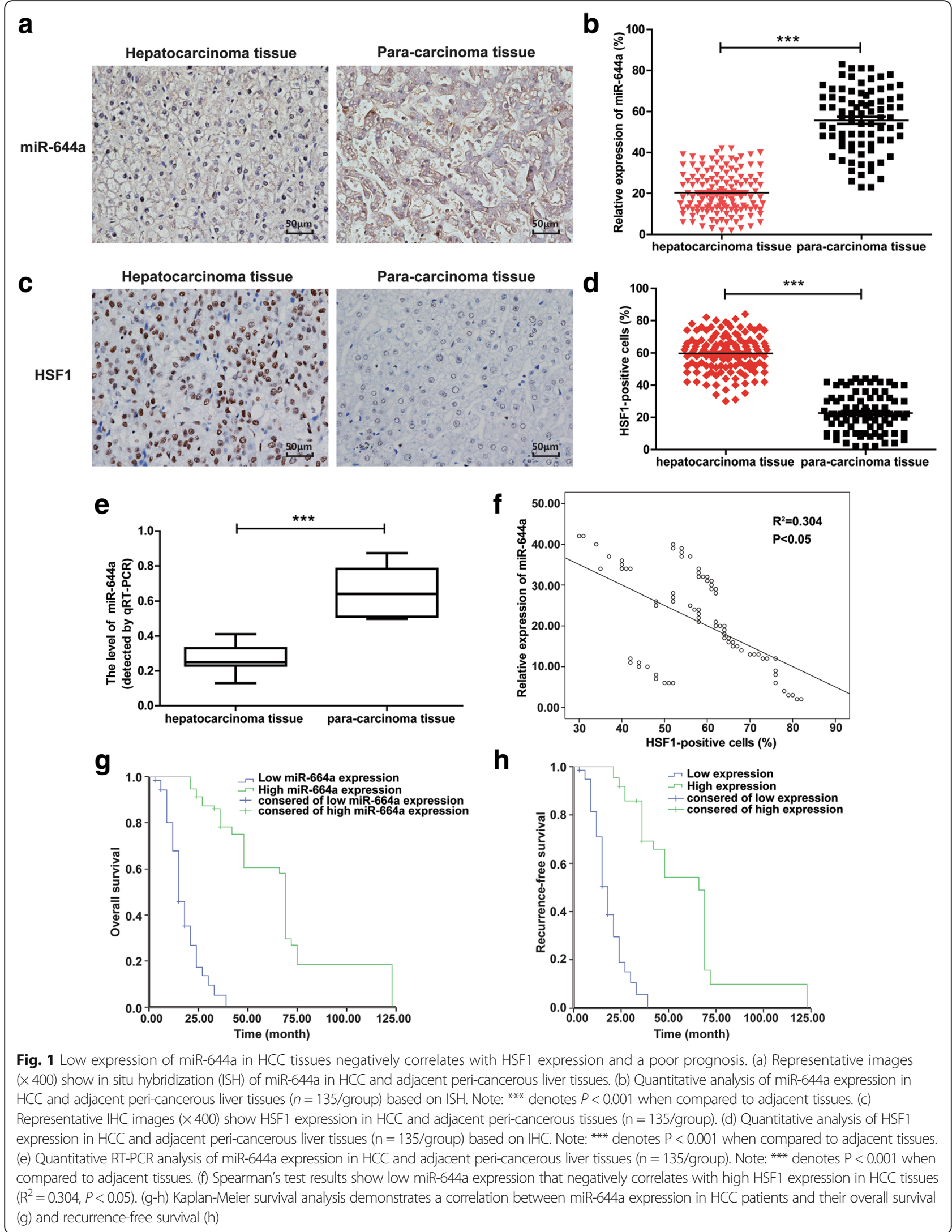


Table 1 Correlations berween miR-644a expression and clinicopathological parameters in 135 hepatocellular carcinoma patients

\begin{tabular}{|c|c|c|c|c|}
\hline \multirow[t]{2}{*}{ Variables } & \multicolumn{2}{|c|}{ miR-644a expression } & \multirow[t]{2}{*}{ Total } & \multirow[t]{2}{*}{$P$ value } \\
\hline & Low (72) & High (63) & & \\
\hline \multicolumn{5}{|l|}{ Age (y) } \\
\hline$<60$ & $21(48 \%)$ & $23(52 \%)$ & 44 & \multirow[t]{2}{*}{0.368} \\
\hline$\geq 60$ & $51(56 \%)$ & $40(44 \%)$ & 91 & \\
\hline \multicolumn{5}{|l|}{ Gender } \\
\hline Male & $48(59 \%)$ & $34(41 \%)$ & 82 & \multirow[t]{2}{*}{0.134} \\
\hline Female & $24(45 \%)$ & $29(55 \%)$ & 53 & \\
\hline \multicolumn{5}{|c|}{ Tumor diameter (cm) } \\
\hline$<5$ & $20(33 \%)$ & $39(67 \%)$ & 59 & \multirow[t]{2}{*}{$0.001^{\mathrm{a}}$} \\
\hline$\geq 5$ & $52(68 \%)$ & $24(32 \%)$ & 76 & \\
\hline \multicolumn{5}{|l|}{ AFP (ng/ml) } \\
\hline$<20$ & 26 & 25 & 51 & \multirow[t]{2}{*}{0.401} \\
\hline$\geq 20$ & 46 & 38 & 84 & \\
\hline \multicolumn{5}{|c|}{ Tumor differentiation } \\
\hline Well & $16(44 \%)$ & $20(56 \%)$ & 36 & \multirow[t]{3}{*}{0.195} \\
\hline Moderate & $27(53 \%)$ & $15(36 \%)$ & 42 & \\
\hline Poor & $29(51 \%)$ & $28(49 \%)$ & 57 & \\
\hline \multicolumn{5}{|l|}{ TNM stage } \\
\hline$|-| \mid$ & 25(39\%) & $39(61 \%)$ & 64 & \multirow[t]{2}{*}{$0.001^{a}$} \\
\hline III-IV & $47(66 \%)$ & $24(34 \%)$ & 71 & \\
\hline \multicolumn{5}{|c|}{ HSF1 expression } \\
\hline Low & 13(34\%) & $25(66 \%)$ & 38 & \multirow[t]{2}{*}{$0.004^{a}$} \\
\hline High & $59(61 \%)$ & $37(39 \%)$ & 96 & \\
\hline
\end{tabular}

Abbreviation: HSF1 heat shock factor 1, AFP alpha-fetoprotein.

${ }^{a}$ Significant $\mathrm{p}$ value

observed that HSF1 silencing decreased proliferation and colony formation (Fig. 5A-B), but increased cellular apoptosis (Fig. 5C). Since miR-644a negatively regulates HSF1 expression, we postulated that up-regulation of HSF1 would increase proliferation and survival of HCC cells.
Therefore, we over-expressed HCC cells with miR-644a mimic and wild type HSF1 or mutant HSF1. We observed that over-expression of wild type HSF1 increased HCC cell proliferation and colony formation (Fig. 6A-B) and decreased apoptosis (Fig. 6C). These data suggest that HSF1 up-regulation reverses the inhibitory effects of miR-644a in HCC cells.

\section{The miR-644a/HSF1 axis modulates expression of BH3 only apoptotic proteins}

To determine the role of the miR-644a/HSF1 axis in HCC, we performed protein chip analysis of apoptosis-related proteins in control and HSF1-siRNA transfected SMMC-7721 cells. HSF1 silencing resulted in changes in the expression of apoptosis-related proteins (Fig. 7A). Furthermore, HSF1 silencing up-regulated many apoptosis-related signalling pathways such as BH3-only apoptotic proteins, DNA damage signalling and HDAC class III regulated apoptotic proteins (Fig. 7B). The BH3-only apoptotic proteins were the most enriched apoptotic pathway (Fig. 7B). These results suggest that the miR-644a/HSF1 axis regulates apoptosis by modulating the expression of BH3-only proteins.

Next, we transfected SMMC-7721 cells with miR-644a mimics to down-regulate HSF1 expression and analysed the expression of BH3-only proteins by western blotting. We observed decreased expression of HSF1, HSP90, $\mathrm{HSP} 60, \mathrm{Bcl}-2$, and $\mathrm{Bcl}-\mathrm{xL}$ proteins and increased expression of BID, BAD, BIM, SMAC, Apaf-1 and cleaved caspases-3 and -9 (Fig. 7C). We further analysed the expression of Bcl-xl and BID in 135 HCC and adjacent normal liver patient tissues. We observed higher Bcl-xL and lower BID expression in HCC tissues than in adjacent normal liver tissues (Additional file 1: Figure S1D \& Additional file 1: Figure S1E). BID expression was inversely correlated with $\mathrm{Bcl}-\mathrm{xL}$ levels in $\mathrm{HCC}$ tissues (Additional file 1: Figure S1C). In addition, we confirmed that the BID and Bcl-xL expression levels in

Table 2 Multivariate Analysis with a Cox Proportional Hazards Regresssion Model

\begin{tabular}{|c|c|c|c|c|c|c|}
\hline \multirow[t]{2}{*}{ Variable } & \multicolumn{3}{|c|}{ Univariate Analysis } & \multicolumn{3}{|c|}{ Multivariate Analysis } \\
\hline & $\mathrm{RR}$ & $95 \% \mathrm{Cl}$ & $\mathrm{P}$ & $\mathrm{RR}$ & $95 \% \mathrm{Cl}$ & $\mathrm{P}$ \\
\hline Age $<45$ years (VS. $>45$ years) & 1.023 & $0.422-2.480$ & 0.960 & 1.300 & $0.479-3.523$ & 0.608 \\
\hline Gender male (VS. female) & 1.016 & $0.553-1.867$ & 0.958 & 0.939 & $0.410-2.148$ & 0.881 \\
\hline Tumor diameter < 2 cm (VS. $>2 \mathrm{~cm}$ ) & 0.726 & $0.384-1.373$ & 0.324 & 0.886 & $0.361-2.177$ & 0.792 \\
\hline AFP < 20 ng/ml (VS. > 20 ng/ml) & 1.144 & $0.616-2.124$ & 0.670 & 2.232 & $1.007-4.948$ & 0.048 \\
\hline Tumor number Solitary (VS. Multiple) & 0.699 & $0.364-1.343$ & 0.283 & 0.407 & $0.153-1.082$ & 0.072 \\
\hline $\begin{array}{l}\text { Tumor differentiation Well or moderate } \\
\text { (VS. poor) }\end{array}$ & 1.378 & $0.716-2.650$ & 0.337 & 0.834 & $0.340-2.051$ & 0.693 \\
\hline TNM stage I-II (VS. III-IV) & 0.568 & $0.287-1.124$ & 0.104 & 0.567 & $0.229-1.404$ & 0.220 \\
\hline miR-644a Low (VS. High) & 0.379 & $0.183-0.784$ & $0.009^{a}$ & 0.379 & $0.146-0.982$ & $0.048^{\circ}$ \\
\hline
\end{tabular}

Abbreviation: $R R$ relative risk, $C l$ confidence interval, AFP alpha-fetoprotein. 

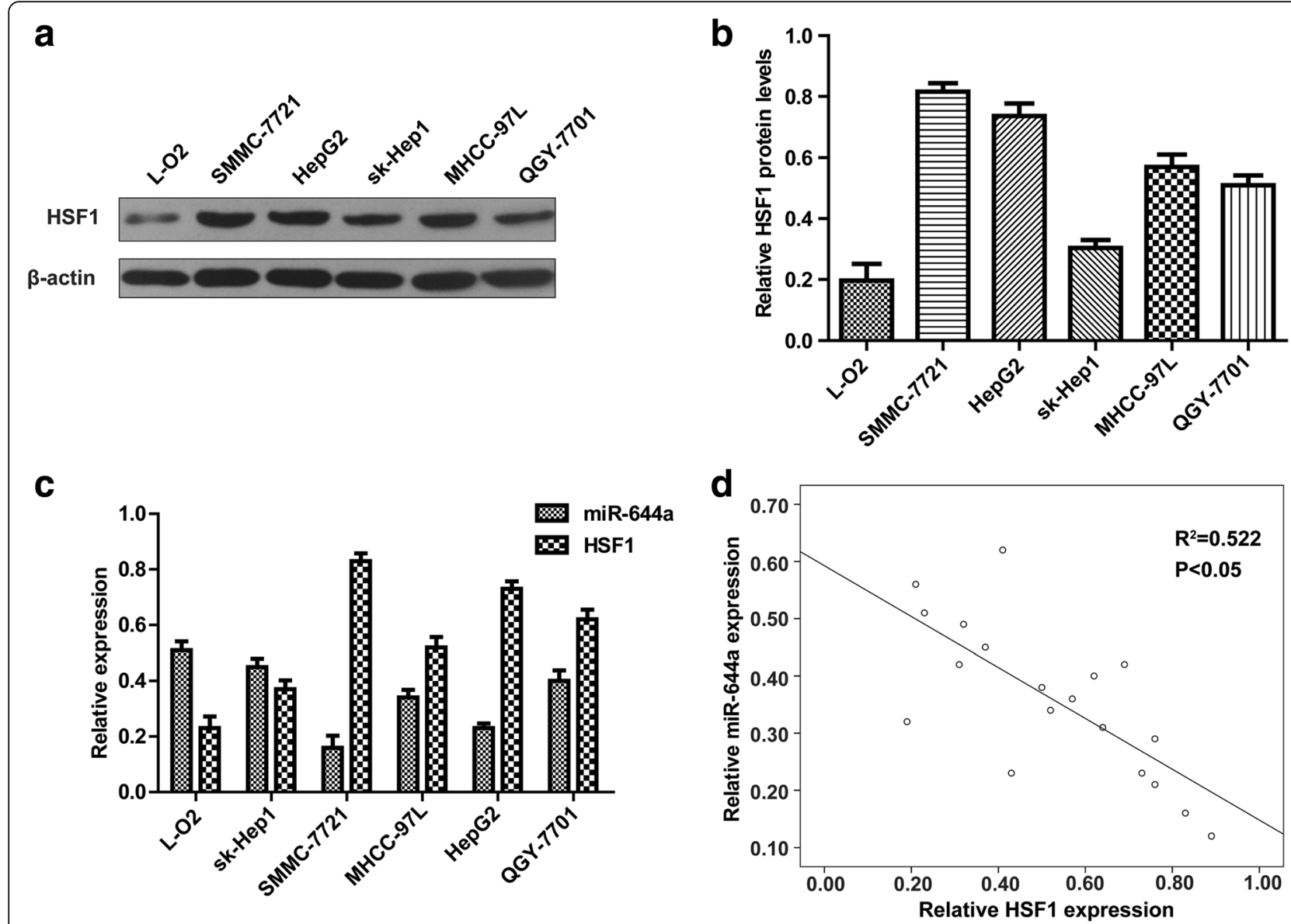

Fig. 2 Correlation between miR-644a and HSF1 expression in HCC cells. (a) Quantitative RT-PCR analysis of miR-644a expression in HCC cell lines, HepG2, SMMC-7721, sk-Hep1, MHCC-97 L, QGY-7701 and the normal liver cells, L-O2. (b) Representative western blot shows HSF1 protein expression in the HCC cell lines HepG2, SMMC-7721, sk-Hep1, MHCC-97 L, and QGY-7701 and the normal liver cells, L-O2. (c) Quantitative RT-PCR analysis of HSF1 mRNA expression in the HCC cell lines, HepG2, SMMC-7721, sk-Hep1, MHCC-97 L, and QGY-7701 and the normal liver cells, L-O2. (d) Spearman's analysis shows a correlation between miR-644a and HSF1 expression in the HCC cell lines $\left(R^{2}=0.522, P<0.05\right)$. Note: Data are represented as the mean \pm SD of three independent experiments and were analysed by a paired t-test

the xenograft model were consistent with that of the cell models (Additional file 2: Figure S2A \& Additional file 2: Figure S2B). These results suggest that the miR-644a/ HSF1 axis regulates BH3-only proteins in the apoptotic pathway.

\section{MiR-644a inhibits in vivo xenograft tumour growth by down-regulating HSF1}

To verify the effects of miR-644a on HCC cell proliferation in vivo, we generated stably transfected SMMC-7721 and HepG2 cell lines with miR-644a mimics and control miRNA. Then, we injected these cells into the right groin region of $\mathrm{BALB} / \mathrm{c}$ nude mice and followed the tumour growth. We sacrificed the nude mice on day 35 and harvested the tumours and weighed them. We observed decreased tumour growth from HCC cells transfected with the miR-644a mimic than in the control groups (Fig. 8A-B). Subsequently, we observed low expression of HSF1 in the miR-644a mimic group tumours by IHC and western blotting (Fig. 8C-D). These results demonstrate that miR-644a inhibits HCC growth and survival by down-regulating HSF1. Thus, our results show that miR-644a inhibits HCC tumourigenesis by inhibiting HSF1 expression and promoting expression of BH3-only proteins (Fig. 9).

\section{Discussion}

MicroRNAs are conserved small noncoding RNAs that regulate gene expression at the post-transcription or translational levels [12]. MicroRNAs also play a key role in tumourigenesis and serve as diagnostic and prognostic biomarkers as well as potential therapeutic targets [13-15]. High miRNA-644a expression inhibits the growth, progression and chemoresistance of oesophageal 


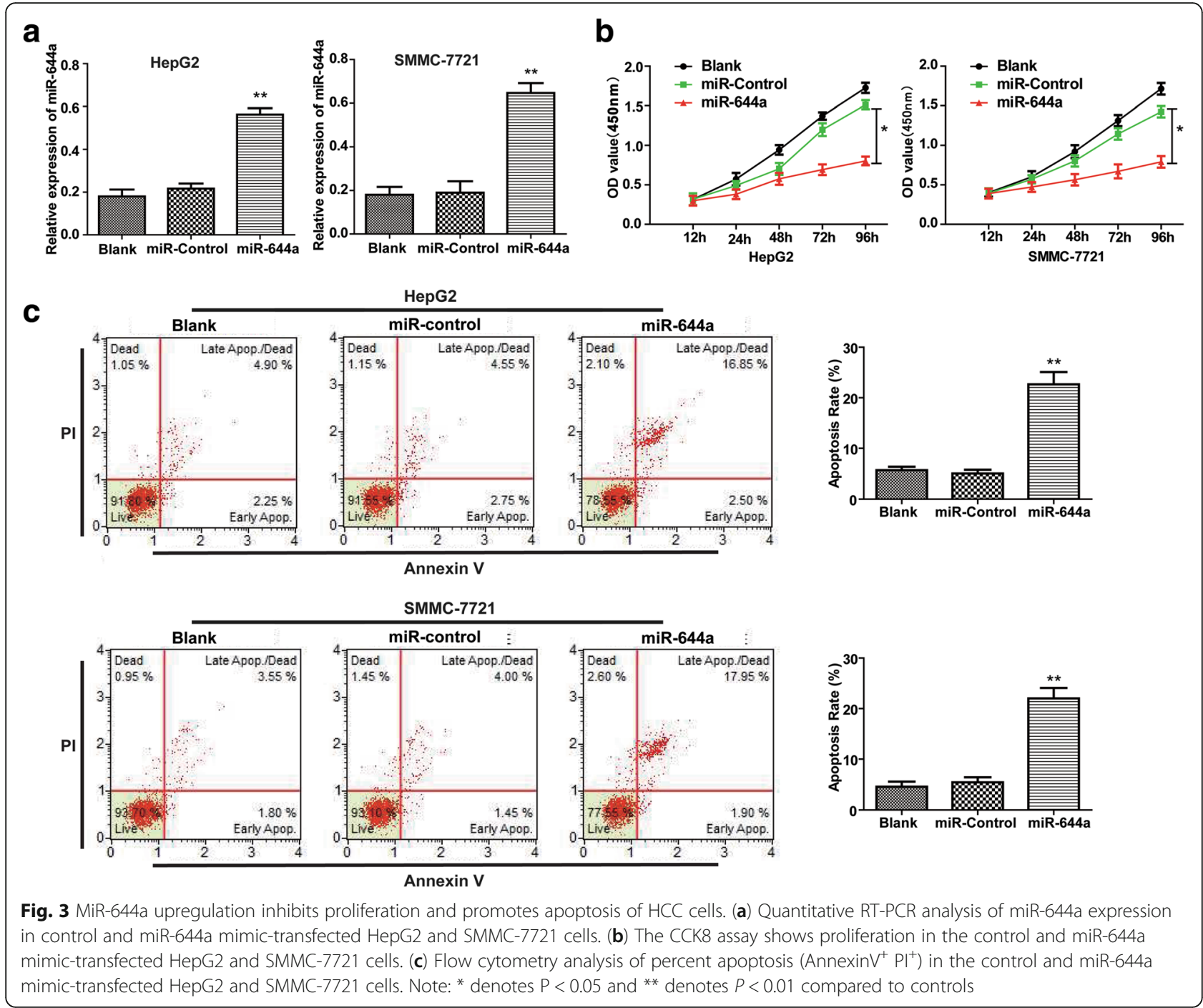

and breast cancers $[8,9]$. However, the role of miR-644a in HCC tumourigenesis is not clear known. Our study demonstrates that miR-644a levels are low in HCC patient tissues and negatively correlated with tumour diameter and TNM stages. This suggests that miR-644a is a potential prognostic factor in HCC patients.

HSF1 is a highly conserved transcription factor that is involved in the regulation of various stress related pathways [16, 17]. Moreover, HSF1 promotes tumour cell proliferation and metabolism by cytoprotective pathways [18-20] and it can also accelerate HCC development and act as a key determinant of HCC development by regulating hepatic steatosis and metabolic syndrome $[21,22]$. It had been found that ablation of HSF1 restrains the growth of c-Myc-derived mouse hepatocellular carcinoma (HCC) cell lines, where it can downregulate of c-Myc levels. Conversely, silencing of c-Myc gene in human and mouse HCC cells led to downregulation of HSF1 expression [23]. Besides, HSF1 inhibition was accompanied by downregulation of the phosphoinositide 3-kinase (PI3K)/AKT/mammalian target of rapamycin (mTOR) cascade and related metabolic pathways, so as to suppresses the growth of hepatocarcinoma cell lines [24]. MiR-34b enhances the apoptosis of acute myeloid leukaemia cells by decreasing HSF1 expression [25]. However, the role of microRNA in regulating HSF1 in HCC has not been reported. Our results demonstrate that miR-644a binds to the 3'-UTR of HSF1 in HCC cells and suppresses its expression. Subsequent induction of the expression of BH3-only proteins promotes apoptosis in HCC cells.

BH3-only proteins are a family of proteins that contain Bcl-2 homology domain 3 (BH3). They are mainly involved in cellular apoptosis and include members such as BIM, BID and NOXA [26, 27]. Excessive endoplasmic reticulum stress results in increased expression of BH3-only proteins, thereby inducing cellular apoptosis 


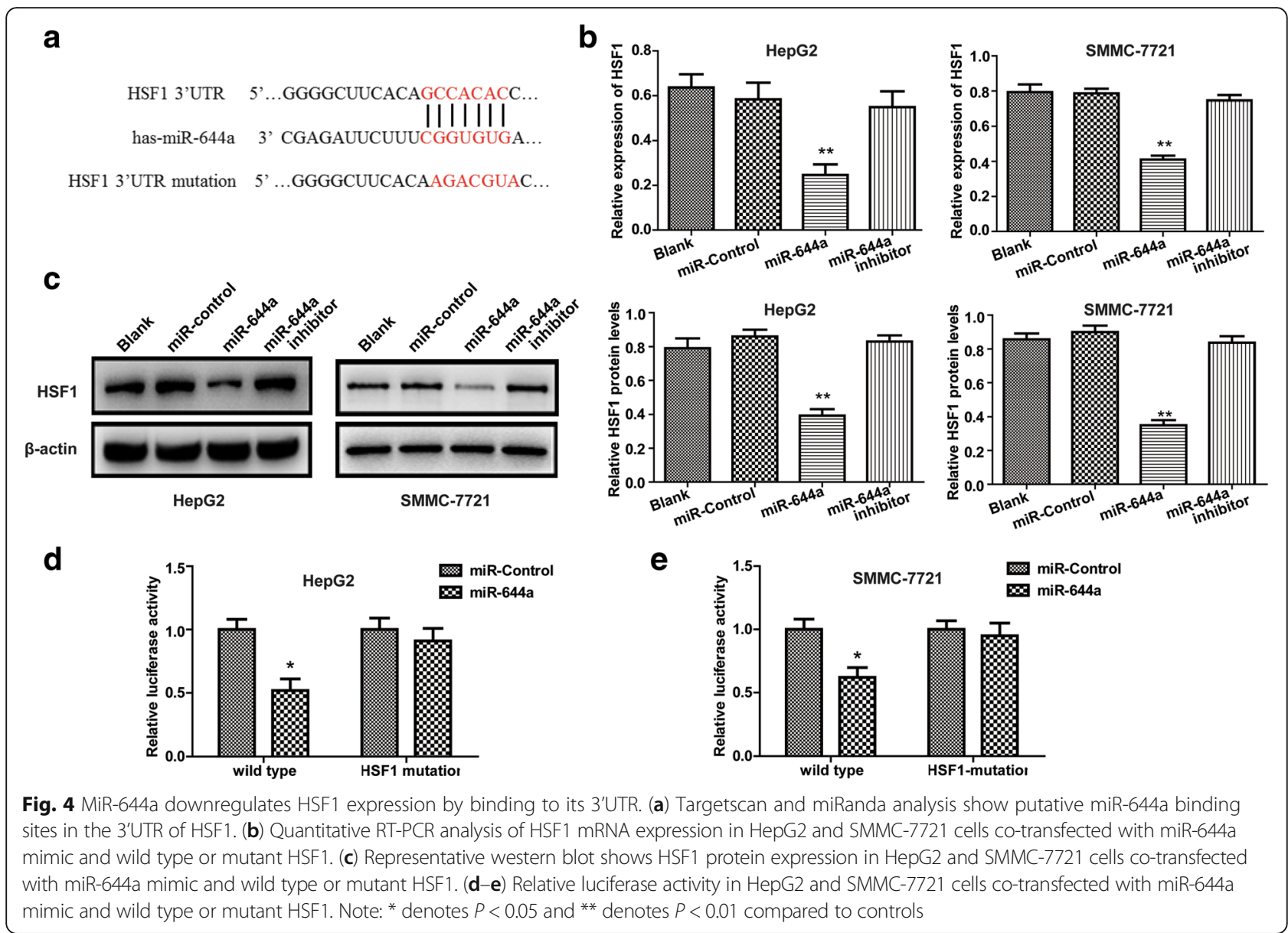

[28, 29]. BH3-only proteins down-regulate BAG3 levels and promote apoptosis of primary glioma cells [30]. Our study shows that BH3-only apoptotic pathway proteins were up-regulated by silencing HSF1 in HCC cells. Increased expression of BH3-only proteins was correlated with miR-644a over-expression. Therefore, we concluded that miR-644a promotes the apoptosis of HCC cells by down-regulating HSF1.

In conclusion, we demonstrate that miR-644a down-regulates HSF1 levels, which induces BH3-only apoptotic proteins that promote $\mathrm{HCC}$ cell apoptosis. Therefore, our study indicates that miR-644a is a potential prognostic biomarker and therapeutic target in HCC.

\section{Materials and methods}

\section{HCC patient samples}

We obtained 135 HCC patient tissue specimens and their corresponding clinical data from the Department of Hepatobiliary and Pancreatic Surgery and Department of Pathology, Affiliated Hospital of Guilin Medical University, China from 2010 to 2016. The clinical data were reviewed and approved by the Ethics Committee of
Guilin Medical University. We obtained written informed consent from all of the patients in accordance with the Declaration of Helsinki. The clinicopathological data included gender, age, tumour diameter, tumour differentiation, and clinical TNM staging of the HCC patients; all patients were classified and graded based on the PTNM classification advocated by the International Union against Cancer and were followed up until June 2017.

\section{In situ hybridization (ISH)}

The in situ hybridization assay to analyse miR-644a expression in HCC tissue samples was performed according to protocols described previously [31]. The miR-644a antisense oligonucleotide probes were obtained from Exiqon, Inc. (Woburn, MA, USA).

\section{Immunohistochemistry}

The 135 pairs of resected HCC and para-cancerous tissues were fixed overnight with $4 \%$ paraformaldehyde, embedded in paraffin and cut into $4 \mathrm{~mm}$ thick sections. Immunohistochemical staining was performed with an 


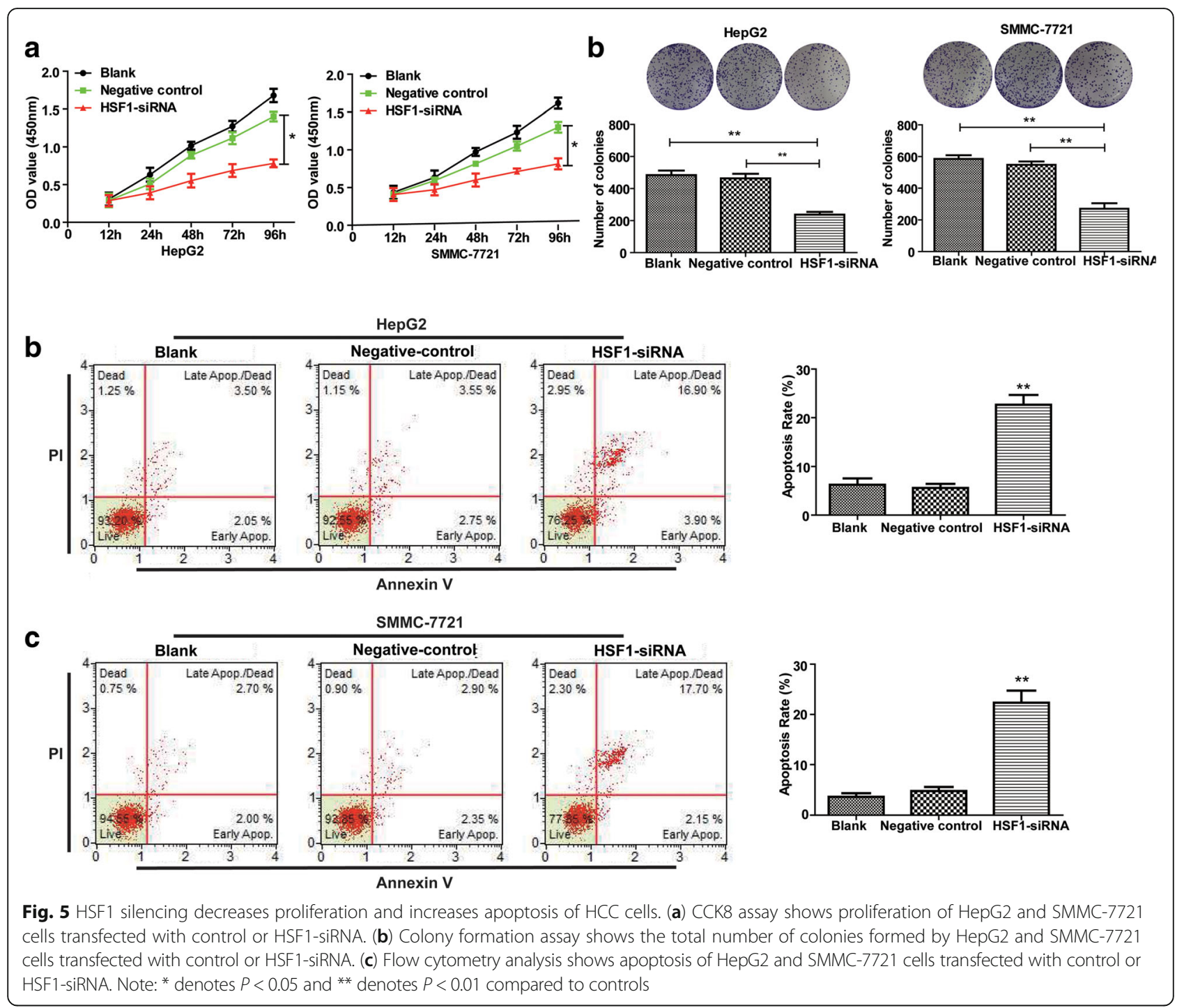

Envision IHC kit (Maxin Biotechnologies Inc., Fuzhou, Fujian, China). Briefly, the tissue sections were dewaxed and hydrated, followed by antigen retrieval with citrate buffer for $15 \mathrm{~min}$ at $100{ }^{\circ} \mathrm{C}$ in a microwave oven. The sections were incubated with the primary antibody against HSF1 (Santa Cruz Biotechnology, Inc., USA) at room temperature for $1 \mathrm{~h}$ at a dilution of 1:200 and were visualized using the UltraVision Quanto Detection System HRP DAB kit (Thermo Scientific) according to the manufacturer's protocols. The stained sections were counterstained with haematoxylin and then developed according to the manufacturer's instructions and scored using an Olympus X71 microscope. Based on the staining intensity, samples were divided into the following grades: 0 : $<10 \%$ positive staining HCC cells; $1+$ : $11-25 \%$ positive staining HCC cells; $2+: 26-50 \%$ positive staining HCC cells; $3+:>50 \%$ positive staining HCC cells. IHC and scoring analysis were performed independently by two investigators.

\section{Western blotting}

Total protein lysates were prepared from HCC cells and tissues in lysis buffer $(50 \mathrm{mM}$ Tris- $\mathrm{HCl}, 137 \mathrm{mM} \mathrm{NaCl}$, $10 \%$ glycerol, $100 \mathrm{mM}$ sodium orthovanadate, $1 \mathrm{mM}$ phenylmethylsulfonyl fluoride (PMSF), $10 \mathrm{mg} / \mathrm{ml}$ aprotinin, $10 \mathrm{mg} / \mathrm{ml}$ leupeptin, $1 \%$ Nonidet P-40, and $5 \mathrm{mM}$ protease inhibitor cocktail; $\mathrm{pH}$ 7.4), and the protein concentration was measured by a BCA (bicinchoninic acid) protein assay (Beyotime, Inc., Shanghai, China). Equal amounts of protein lysates were separated on $10 \%$ SDS-PAGE at $100 \mathrm{mV}$ for $2 \mathrm{~h}$. Then, the separated proteins were transferred onto PVDF membranes at $80 \mathrm{mV}$ for $1 \mathrm{~h}$. The blots were first blocked with 5\% nonfat milk, followed by incubation with primary 


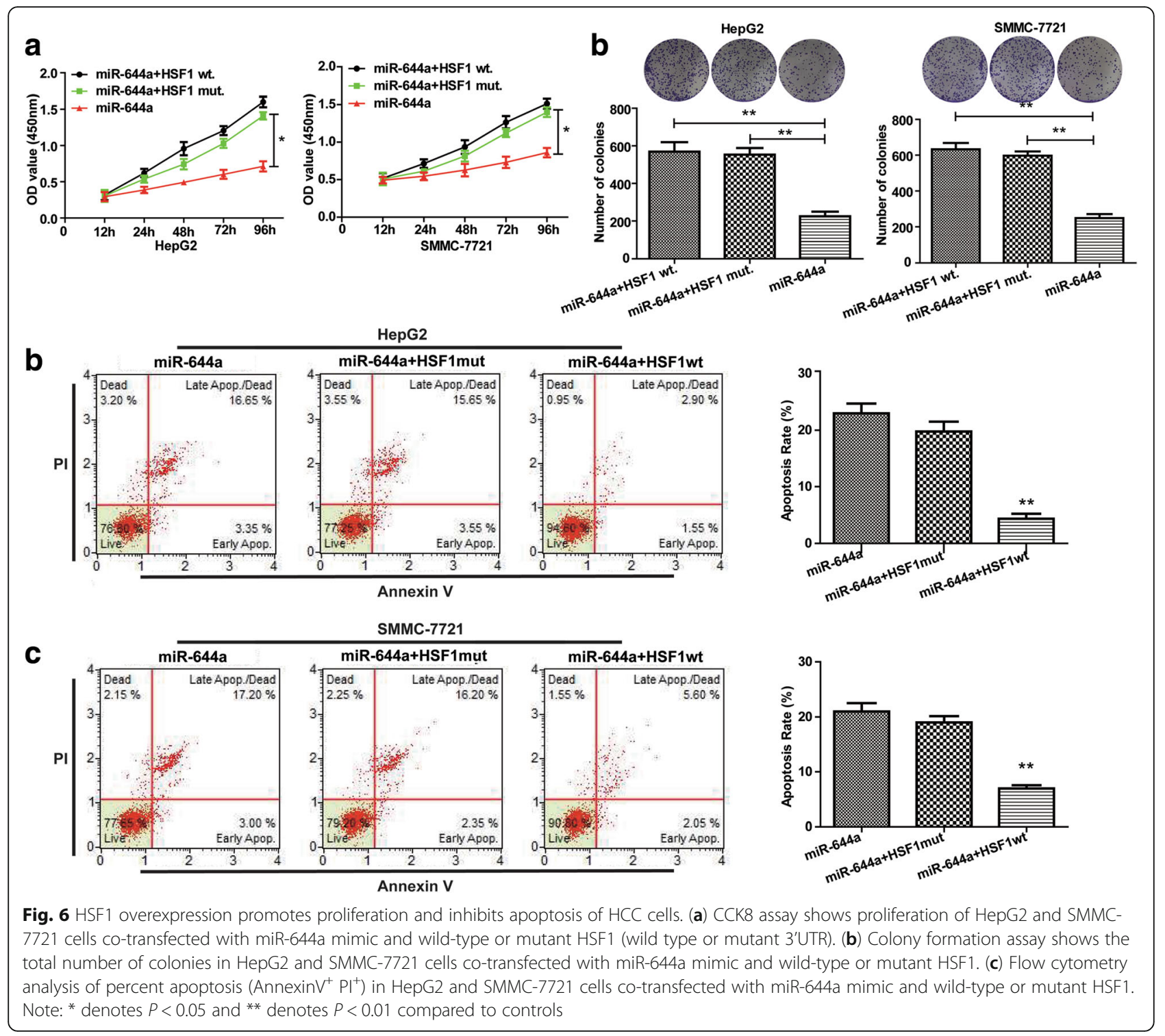

antibodies overnight at $4{ }^{\circ} \mathrm{C}$. The blots were then incubated with HRP-conjugated secondary antibody at room temperature for $1 \mathrm{~h}$. Then, the blots were developed by an ECL chemiluminescence method and the specific protein bands were quantified with ImageJ software. $\beta$-Actin was used as an internal control. Antibodies against HSF1, caspase 3, caspase 9, BAD, Bcl-2, Bcl-xL, BIM and BID were purchased from Santa Cruz (Dallas, Texas, USA). Antibodies against $\beta$-actin, HSP90, HSP60, SMAC and Apaf-1 were purchased from Origene (Rockville, MD, USA).

\section{Quantitative reverse transcription polymerase chain reaction (qRT-PCR)}

Total RNA was extracted from HCC cells and tissues with TRIzol (Thermofisher Inc., Grand Island, NY, USA) and an RNAiso ${ }^{\text {Tax }}$ Plus kit (Takara, Japan) according to the manufacturer's instructions. The RNA concentration was determined in a Beckman spectrophotometer (Beckman Coulter, USA). Reverse transcription was performed with the Fast Quant first strand cDNA synthesis Kit (TIANGEN, China). Then, we performed real-time PCR with Fast Start Universal SYBR Green Master Mix (Roche Diagnostics GmbH Mannheim, Germany) in an Applied Biosystems real-time PCR machine (Thermo Fisher Scientific, USA).

\section{Cell culture and transfections}

We obtained HCC cells (HepG2, SMMC-7721, sk-Hep1, MHCC-97 L, and QGY-7701) and normal liver cells (L-O2) from the Chinese Academy of Sciences cell bank (Shanghai, China). HepG2, sk-Hep1 and MHCC-97 L were grown in Dulbecco's modified 


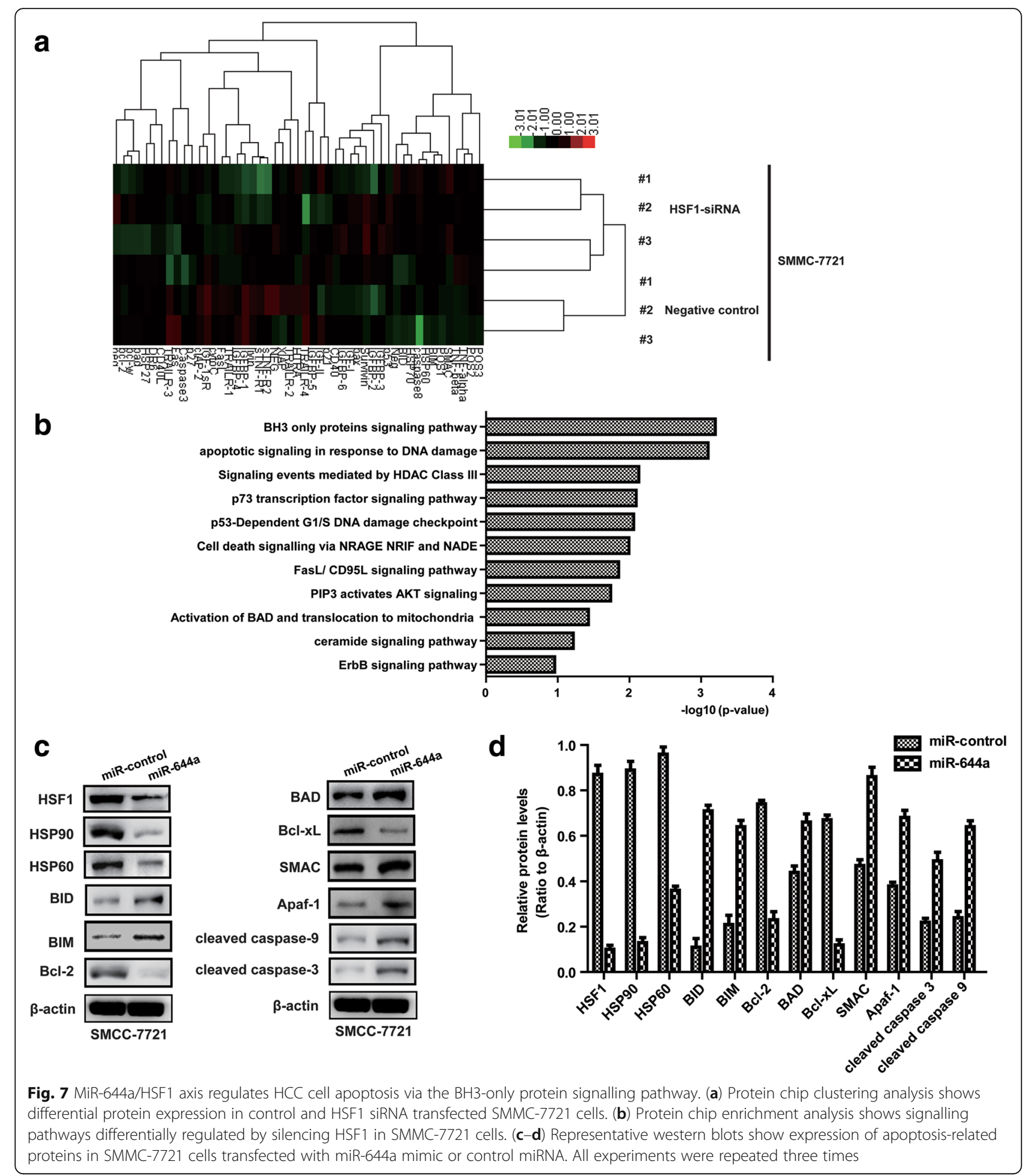

Eagle medium (Thermo Fisher Scientific, South America), and SMMC-7721, QGY-7701 and L-O2 cells were grown in RPMI-1640 medium (Thermo Fisher Scientific) supplemented with $10 \%$ foetal bovine serum (Thermo Fisher Scientific) at $37{ }^{\circ} \mathrm{C}$ and $5 \% \mathrm{CO}_{2}$. The transfection of miR-644a mimic and
HSF1-siRNA were prepared and used according to a previously described protocol [32].

\section{CCK-8 cell proliferation assay}

HCC cells were seeded in 96-well plates $\left(3 \times 10^{3}\right.$ cells in $100 \mu \mathrm{l}$ per well). At different time points, $10 \mu \mathrm{l}$ of cell 


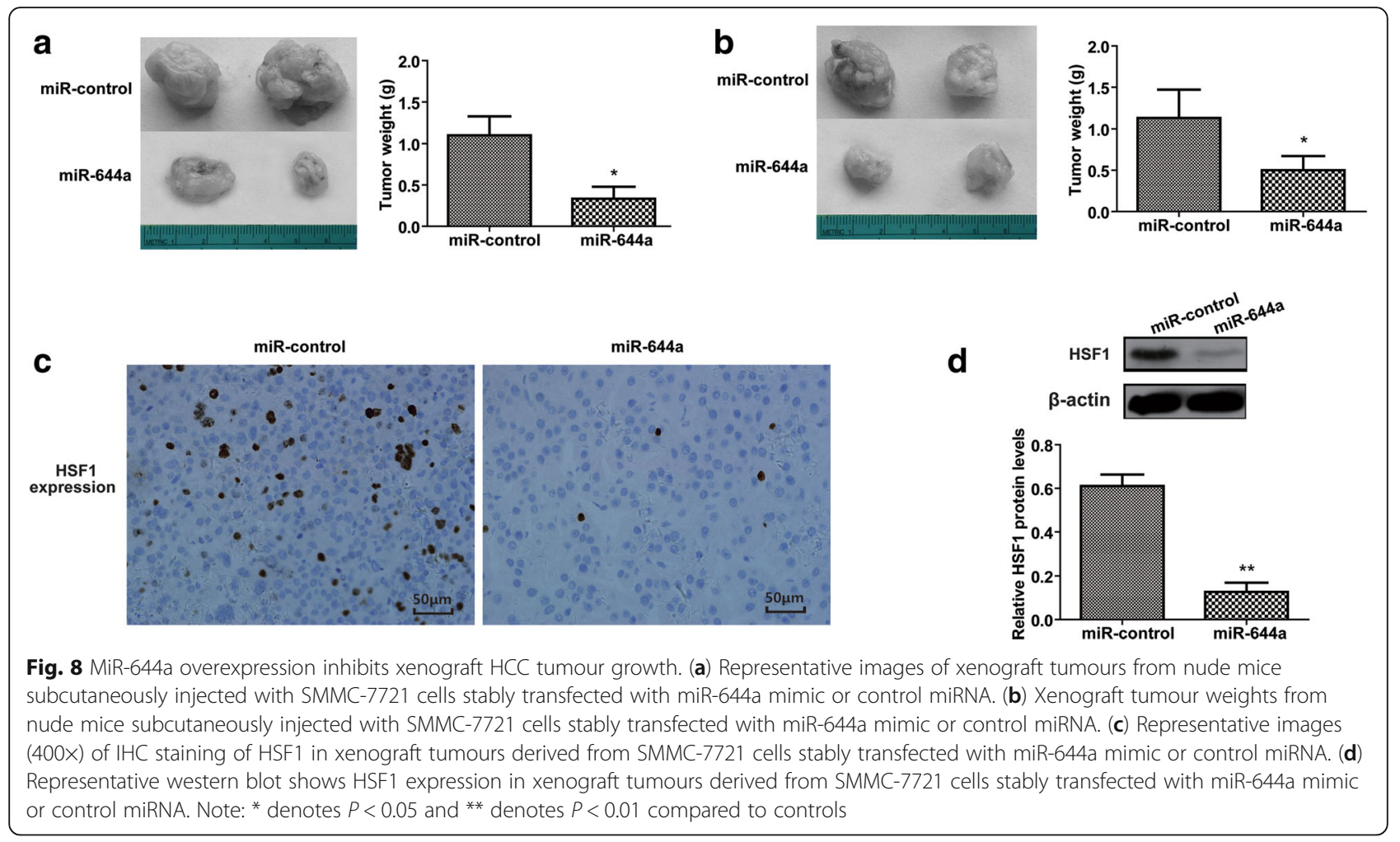

counting kit-8 (CCK-8) solution (Dojindo, Shanghai, China) was added and incubated for 1-3 h. Absorbance was read at $450 \mathrm{~nm}$ in a microplate reader (Spectramax plus384, Molecular Devices, USA).

\section{Flow cytometry analysis of apoptosis}

After various treatments, HCC cells were washed twice with $1 \times$ PBS and centrifuged. Then, $100 \mu \mathrm{l}$ of FITC-conjugated Annexin-V and PI (Sigma, USA) was added and the cells were incubated for $20 \mathrm{~min}$ at room temperature in the dark. Then, the cells were subjected to flow cytometric analysis (Merck Millipore, Germany). The percentage of apoptotic cells (Annexin $\mathrm{V}+\mathrm{PI}+$ ) was determined by using FlowJo software 7.6 (Treestar, USA).

\section{Colony formation assays}

We seeded $600 \mathrm{HCC}$ cells per well in a six-well plate for approximately two weeks in 10\% DMEM or RPMI

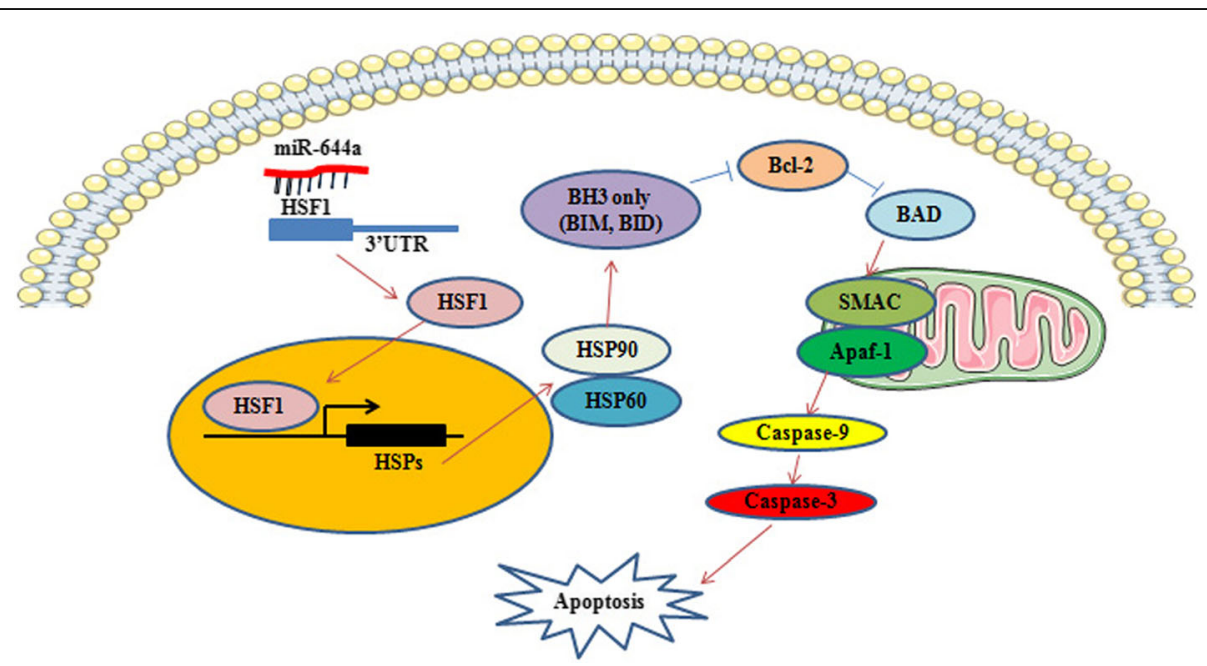

Fig. 9 Schematic diagram of apoptosis regulation in HCC cells by miR-644a 
medium supplemented with $10 \%$ foetal bovine serum. Then, the colonies were fixed with $4 \%$ paraformaldehyde for $20 \mathrm{~min}$ and stained with 1\% crystal violet (G1062, Solarbio, Japan) overnight. After washing the cells three times, the total number of colonies ( $>10$ cells per colony) per well was determined for all conditions. Images were also captured for documentation.

\section{Dual luciferase reporter assay}

We identified the miR-644a target site in the HSF13'UTR with TargetScan 6.2 (http://www.targetscan.org/ vert_71/). We then designed primers to generate the mutant and wild type HSF1 based on the HSF1 mRNA sequence in NCBI GenBank. We PCR amplified the miR-644a target sequence in HSF1 from the total RNA from the HCC cells. The mutant version of the HSF1 3'UTR was generated by overlapping PCR with mutagenic primers. We cloned both wild-type and mutant HSF1-3'UTR sequences into the pMIR-REPORT-basic vector (Applied Biosystems, USA) and confirmed the products by DNA sequencing. For the luciferase reporter assay, we seeded $3 \times 10^{3}$ cells in 24-well plates and co-transfected $100 \mathrm{ng}$ of the luciferase reporter vector with $20 \mathrm{nM}$ miR-644a mimic or miRNA negative control into SMMC-7721 cells. The cells were lysed after $48 \mathrm{~h}$, and the dual luciferase activities were determined using the luminescence reporter gene assay system (PerkinElmer, Norwalk, CT, USA) according to the manufacturer's instructions.

\section{Generation of stable miR-644a over-expressing HCC cell lines}

We purchased lentivirus pEZX-MR04 plasmid clones with miR-644a mimics and negative control miRNA from GenePharma (Shanghai, China) and transfected them into HEK293T cells with EndoFectin Lenti transfection reagent (GeneCopoeia, Rockville, USA). The cells were centrifuged after $48 \mathrm{~h}$ at $10000 \mathrm{rpm}$ for $10 \mathrm{~min}$, and the lentiviral particles expressing miR-644a or negative control miRNAs in the supernatant were concentrated by ultrafiltration. Then, SMMC-7221 cells were infected with lentiviruses expressing miR-644a or negative control miRNAs in the presence of $2 \mu \mathrm{g} / \mathrm{ml}$ puromycin and cultured for 2 weeks to obtain stably transfected cells. The expression of miR-644a in the stably transfected control and miR-644a overexpressing SMMC-7221 cells was determined by qRT-PCR.

\section{Xenograft nude mice model of in vivo tumourigenesis}

We purchased forty 5-6-week-old male BALB/c nude mice from the Animal Experimental Center of Guilin Medical University. All animal experiments were approved by the Animal Care and Use Committee of Guilin Medical University. We randomly divided the nude mice into two groups and injected them subcutaneously into the right inguinal region with $200 \mu \mathrm{l}(2 \times$ $10^{7}$ ) of SMMC-7221 cells that were stably transfected with either empty plasmid (control) or miR-644a mimic (experimental). Tumour growth was recorded at 7, 14, 21,28 and 35 days. Then, the mice were sacrificed by cervical dislocation on day 35; the tumours were harvested by resection and weighed.

\section{Protein chip analysis}

We incubated the protein samples isolated from miR-644a overexpressing and control SMMC-7221 cells with the antibody chip AAH-APO-G1-8 (RayBiotech, Norcross, GA, USA). Then, the unbound proteins were removed by washing and the bound proteins were analysed by fluorescence scanning. We determined the differential expression of the proteins and performed clustering analysis with Cluster v3.0 software (Stanford University, USA). Then, we annotated the differentially expressed proteins and determined the molecular networks by gene ontology and KEGG enrichment analysis.

\section{Statistical analysis}

The statistical analysis was performed with GraphPad Prism 5 (GraphPad Software, Inc., San Diego, CA, USA) and SPSS v.18.0 (SPSS Inc., Chicago, IL, USA). The relationship between miR-644a expression and clinicopathological data was evaluated by the chi-square test $\left(x^{2}\right)$. Quantitative data was analysed by the paired $t$ test. Kaplan-Meier analysis was performed to estimate the survival rate and prognosis of patients with $\mathrm{HCC}$ expressing high or low miR-644a and HSF1 levels. The logarithmic rank test was used to compare the survival curves between different groups. All experiments were repeated three times, and the data are expressed as the mean \pm SD. $P<0.05$ was considered statistically significant.

\section{Additional files}

Additional file 1: Figure S1. (A-B) ROC curve analysis of miR-644a and HSF1 expression in HCC tissues. (C) Correlation between BID and BCl-xL expression in HCC tissues by immunohistochemistry. (D-E) Representative images $(\times 200)$ show immunohistochemical analysis of $\mathrm{BCl}-\mathrm{xL}$ and $\mathrm{BID}$ expression in HCC and adjacent peri-cancerous tissues. Note: *** denotes $P<0.001$ when compared to adjacent tissues. (PDF $6242 \mathrm{~kb}$ )

Additional file 2: Figure S2. (A-B) Representative images (400X) of $\mathrm{HC}$ staining of BID and BCL-XL in xenograft tumours derived from SMMC-7721 cells stably transfected with miR-644a mimic or control miRNA. Note: *** denotes $P<0.05$ when compared to adjacent tissues. (TIF 3954 kb)

\section{Acknowledgements}

We wish to particularly acknowledge the patients enrolled in this study for their participation, and the Department of Pathology and Physiopathology, Guilin Medical University, for its collaboration in providing the human samples and the clinical information used in this project with appropriate ethics approval. 


\section{Funding}

This research was supported in part by The National Natural Science Foundation of China (No. 81360367, No. 81560393), Guangxi Science Fund for Distinguished Young Scholars Program (2016GXNSFFA380003), Natural Science Foundation of Guangxi (2014GXNSFBA118192, 2015jjDA40010), Guangxi health department raise issue (Z2013466), Fund project in Guangxi department of education (YB2014265), Guangxi Regional High-risk Tumors Early Prevention and Control of Key Laboratory Open Research Project (GK2014-TKF01), Scientific Research and Technology Development Project for Guilin (20140310-2-2). Open Funds of The Guangxi Key Laboratory of Tumor Immunology and Microenvironmental (2018KF001)

\section{Authors' contributions}

BT, ZRW conceived and designed the experiments. WJL and YL performed the experiments. ZML, YW, SQZ, XCX, FLR analyzed the data. BT, ZRW supervised the whole experimental work and revised the manuscript. WJL wrote the paper. All authors read and approved the manuscript.

\section{Ethics approval and consent to participate}

Clinical data have been approved by the Ethics Committee of Guilin Medical. University and approved by the patients. All animal experiments were approved by Animal Care and Use Committee of Guilin Medical University.

\section{Competing interests}

No potential conflicts of interest were disclosed by all authors.

\section{Publisher's Note}

Springer Nature remains neutral with regard to jurisdictional claims in published maps and institutional affiliations.

Received: 26 February 2018 Accepted: 1 June 2018

Published online: 14 June 2018

\section{References}

1. Sia D, Villanueva A, Friedman SL, Llovet JM. Liver Cancer cell of origin, molecular class, and effects on patient prognosis. Gastroenterology. 2017; 152(4):745-61.

2. Siegel RL, Miller KD, Jemal A. Cancer statistics, 2017. CA Cancer J Clin. 2017; 67(1):7-30.

3. Chen W, Zheng R, Baade PD, Zhang S, Zeng H, Bray F, et al. Cancer statistics in China, 2015. CA Cancer J Clin. 2016;66(2):115-32.

4. Bartel DP. MicroRNAs: genomics, biogenesis, mechanism. and function Cell. 2004;116(2):281-97.

5. Griffiths-Jones S, Grocock RJ, van Dongen S, Bateman A, Enright AJ miRBase: microRNA sequences, targets and gene nomenclature. Nucleic Acids Res. 2006;34(Database issue):D140-4.

6. Di Leva G, Garofalo M, Croce CM. MicroRNAs in cancer. Annu Rev Pathol. 2014;9:287-314.

7. Yang N, Ekanem NR, Sakyi CA, Ray SD. HCC and microRNA: new perspectives on therapeutics and diagnostics. Adv Drug Deliv Rev. 2015;81:62-74.

8. Zhang JX, Chen ZH, Xu Y, Chen JW, Weng HW, Yun M, et al. Downregulation of MicroRNA-644a promotes esophageal squamous cell carcinoma aggressiveness and stem cell-like phenotype via dysregulation of PITX2. Clin Cancer Res : an official journal of the American Association for Cancer Research. 2017;23(1):298-310.

9. Raza U, Saatci O, Uhlmann S, Ansari SA, Eyupoglu E, Yurdusev E, et al. The miR-644a/CTBP1/p53 axis suppresses drug resistance by simultaneous inhibition of cell survival and epithelial-mesenchymal transition in breast cancer. Oncotarget. 2016;7(31):49859-77.

10. Baird NA, Douglas PM, Simic MS, Grant AR, Moresco JJ, Wolff SC, et al. HSF1-mediated cytoskeletal integrity determines thermotolerance and life span. Science (New York, NY). 2014;346(6207):360-3.

11. Tang Z, Dai S, He Y, Doty RA, Shultz LD, Sampson SB, et al. MEK guards proteome stability and inhibits tumor-suppressive amyloidogenesis via HSF1. Cell. 2015;160(4):729-44.

12. Jonas $\mathrm{S}$, Izaurralde $\mathrm{E}$. Towards a molecular understanding of microRNAmediated gene silencing. Nat Rev Genet. 2015;16(7):421-33.

13. Zhang Y, Lin C, Liao G, Liu S, Ding J, Tang F, Wang Z, Liang X, Li B, Wei Y, Huang Q, Li X, Tang B. MicroRNA-506 suppresses tumor proliferation and metastasis in colon cancer by directly targeting the oncogene $\mathrm{EZH} 2$. Oncotarget. 2015;6(32):32586-601.
14. Hammond SM. An overview of microRNAs. Adv Drug Deliv Rev. 2015;87:3-14.

15. Berindan-Neagoe I, Monroig Pdel C, Pasculli B, Calin GA. MicroRNAome genome: a treasure for cancer diagnosis and therapy. CA Cancer J Clin. 2014:64(5):311-36.

16. Vihervaara A, Sistonen L. HSF1 at a glance. J Cell Sci. 2014;127(Pt 2):261-6.

17. Li Y, Xu D, Bao C, Zhang Y, Chen D, Zhao F, et al. MicroRNA-135b, a HSF1 target, promotes tumor invasion and metastasis by regulating RECK and EVI5 in hepatocellular carcinoma. Oncotarget. 2015;6(4):2421-33.

18. Scherz-Shouval R, Santagata S, Mendillo ML, Sholl LM, Ben-Aharon I, Beck $\mathrm{AH}$, et al. The reprogramming of tumor stroma by HSF1 is a potent enabler of malignancy. Cell. 2014;158(3):564-78.

19. Santagata S, Mendillo ML, Tang YC, Subramanian A, Perley CC, Roche SP, et al. Tight coordination of protein translation and HSF1 activation supports the anabolic malignant state [J]. Science. 2013;341(6143):250.

20. Kourtis N, Moubarak RS, Aranda-Orgilles B, Lui K, Aydin IT, Trimarchi T, et al. FBXW7 modulates cellular stress response and metastatic potential through HSF1 post-translational modification. Nat Cell Biol. 2015;17(3):322-32.

21. Chuma M, Sakamoto N, Nakai A, Hige S, Nakanishi M, Natsuizaka M, et al. Heat shock factor 1 accelerates hepatocellular carcinoma development by activating nuclear factor-kB/mitogen-activated protein kinase []]. Carcinogenesis. 2013;58(2):272.

22. Jin X, Moskophidis D, Mivechi NF. Heat shock transcription factor 1 is a key determinant of HCC development by regulating hepatic steatosis and metabolic syndrome [J]. Cell Metab. 2011;14(1):91-103.

23. Cigliano A, Pilo MG, Li L, Simile MM, Latte M. Et al. deregulated c-Myc requires a functional HSF1 for experimental and human hepatocarcinogenesis []]. Oncotarget. 2017;8(53):90638.

24. Cigliano A, Wang C, Pilo MG, Szydlowska M, Brozzetti S, et al. Inhibition of HSF1 suppresses the growth of hepatocarcinoma cell lines in vitro and AKTdriven hepatocarcinogenesis in mice.[J]. Oncotarget. 2017;8(33):54149-59.

25. Li G, Song Y, Zhang Y, Wang H, Xie J. miR-34b targets HSF1 to suppress cell survival in acute myeloid leukemia. Oncol Res. 2016;24(2):109-16.

26. $\mathrm{Ni}$ Chonghaile T, Letai A. Mimicking the BH3 domain to kill cancer cells. Oncogene. 2008;27(Suppl 1):S149-57.

27. Kang MH, Reynolds CP. BCl-2 inhibitors: targeting mitochondrial apoptotic pathways in cancer therapy. Clinical cancer research : an official journal of the American Association for Cancer Research. 2009;15(4):1126-32.

28. Mani J, Antonietti P, Rakel S, Blaheta R, Bartsch G, Haferkamp A, Kogel D. Knockdown of BAG3 sensitizes bladder cancer cells to treatment with the BH3 mimetic ABT-737. World J Urol. 2016;34(2):197-205.

29. Glab JA, Doerflinger M, Puthalakath H. BH3-only proteins: the thorny end of the ER stress response. Cell Death Dis. 2017;8(6):e2889.

30. Antonietti $P$, Linder B, Hehlgans S, Mildenberger IC, Burger MC, Fulda S, Steinbach JP, Gessler F, Rodel F, Mittelbronn M, Kogel D. Interference with the HSF1/HSP70/BAG3 pathway primes glioma cells to matrix detachment and BH3 mimetic-induced apoptosis. Mol Cancer Ther. 2017:16(1):156-68.

31. Chen H, Ren C, Han C, Wang D, Chen Y, Fu D. Expression and prognostic value of miR-486-5p in patients with gastric adenocarcinoma. PLoS One. 2015;10(3):e0119384

32. Li F, Mahato RI. RNA interference for improving the outcome of islet transplantation. Adv Drug Deliv Rev. 2011;63(1-2):47-68.

\section{Ready to submit your research? Choose BMC and benefit from:}

- fast, convenient online submission

- thorough peer review by experienced researchers in your field

- rapid publication on acceptance

- support for research data, including large and complex data types

- gold Open Access which fosters wider collaboration and increased citations

- maximum visibility for your research: over $100 \mathrm{M}$ website views per year

At BMC, research is always in progress.

Learn more biomedcentral.com/submissions 